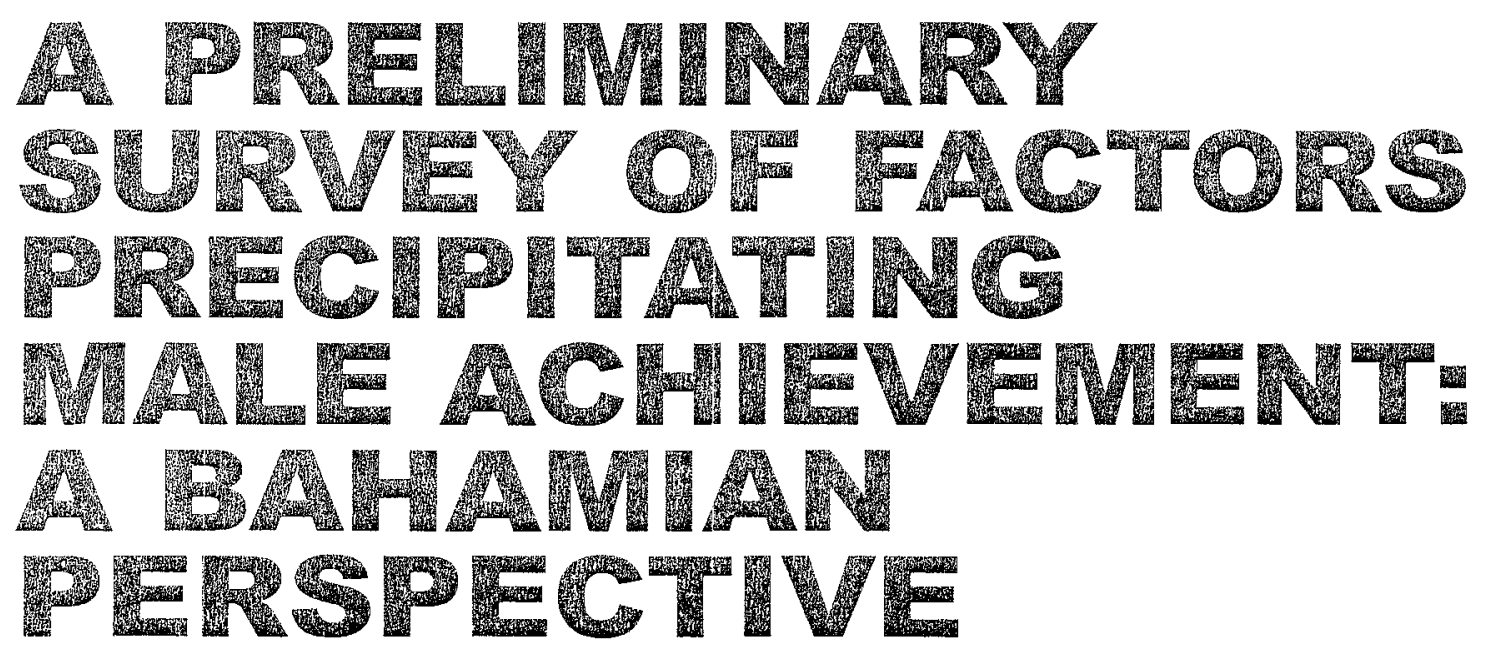

J. Minnis, S. Plumridge, C. Ward

The College of The Bahamas

https://doi.org/10.15362/ijbs.v11io.47

\title{
ADS S RACT
}

Male underachievement has received considerable attention in recent years. It is of particular concern in The Bahamas given the overrepresentation of females at the tertiary level of education. This pilot study was designed in conjunction with Kent State University and is one component of a larger project that includes subjects in the USA. The goal was to explore the factors that are believed to influence male achievement present at the primary school level. Some of the factors include personal perception, parental involvement, teaching style, the structure of schools, lack of male role models and socio-economic factors. Structured interviewing techniques were used to gather data from a sample of Bahamian males from grades 3,4 and 5 , their parents and teachers. Results indicate male students have a positive attitude toward school and report encouragement and support from their families. Teachers tended to have a discrepant view of parental involvement. A strong female familial influence is apparent. Additional research is recommended focusing on males at different levels of education and investigating the discrepancies between potential and achievement.

The College of The Bahamas, in conjunction with Kent State University, completed this initial research project seeking to identify factors evident at the primary school level that influence male underachievement. In this pilot study the focus was a sample of third, fourth and fifth grade males and teachers from selected public schools in New Providence. 
Several factors have been identified internationally as contributing to male underachievernent at all levels of educational systems. Frequently reported are personal responsibility, self-perception, level of parental involvement, attitudes toward schooling, the attitude of teachers toward male students, teaching styles, the structure of schools, the lack of male role models, peer relationships, and socioeconomic conditions including family composition (e.g., Allen \& Kickbusch, 1998, Bridges, 1999; Ford \& Thomas, 1997; Francis, 1999; Lee, 1991, 2001; Noguera, 1996).

In The Bahamas anecdotal evidence suggests that a crisis in academic achievement for young black Bahamian males also exists, yet a review of the literature reveals that the issue has received little empirical attention. Reports of a standardized achievement test, the GLAT (Grade Level Assessment Test), indicate that for the years 1999 and 2000, the majority of Bahamian third and sixth grade students were performing at the average and above average level in Language Arts, Writing and Mathematics. According to The Bahamas Ministry of Education, at the primary level, $34 \%$ of boys perform at the above average level, while at the secondary school level, this figure rose to $43.1 \%$ (Stubbs, 1999-2000). In terms of the Bahamas General Certificate of Secondary Education (BGCSE) for the year 2000, girls performed better than boys, receiving $65 \%$ of the total awarded $\mathrm{A}$ to $\mathrm{C}$ grades. In a UNESCO report the Ministry of Education suggests that nationally, the level of curriculum mastery exhibited by many Bahamian graduates of the school system falls below accepted levels and that underachievement is more apparent in male students (UNESCO, 2000). The report, however, does not specify significant differences between males and females for achievement in literacy for example, but does imply that if differences do exist they may be attributed to reluctance on the part of males to capitalise on educational opportunities at all levels. It is notable that although there is no apparent difference between the number of males and females attending primary and secondary schools in The Bahamas, recent statistics from both The College of The Bahamas and Bahamas Baptist Community College indicate that the ratio of female-to-male students is 3:1 and at Success Training College the ratio is 5:I (Rolle, 2000). In addition, the majority of individuals attending adult literacy and continuing education programmes offered by the government and private enterprise are females (UNESCO, 2000).

As well as academic factors, such as the school culture's lack of appeal to males, a paucity of male teachers as role models, and the attitude of female teachers toward male students, male underachievement is frequently attributed to a social/domestic factors. These include a prevalence of single female-headed households and females moving into male-dominated careers. Documented studies to support these suppositions in The Bahamas are generally lacking. It is interesting that only seven percent of teachers in the public school system are male, and are concentrated at the high school level (Stubbs, 1999-2000). In The Bahamas, females are four times more likely than males to be single heads-of-households. On the other hand, modern Bahamian society continues to reflect a traditional gender split in terms of career choice. According to available census data (Ministry of Economic Development, 1997), a higher concentration of males are found in occupational categories such as legislators, senior officials and managers, professionals (with the exception of teachers), technicians, skilled labourers and manufacturing. Although females attain higher levels of education, the 
apparent presence of more males in these positions suggests that generally, in the job market, males may recover from their tendency not to complete educational training.

Based on international research indicating precipitating influences on male academic underachievement and the anecdotal evidence from the various sectors supporting similar patterns in The Bahamas, this pilot study sought to explore the factors evident at the primary school level that may be influential in academic achievement for Bahamian males.

\section{Method}

During the month of March 2000, random samples of students and teachers were selected from government primary schools in New Providence. Of the 26 primary schools, eight were selected that were representative of the primary school population and the community. Four boys were randomly selected from grades three, four and five respectively in each school for a total sample of 108 . One teacher in each school was randomly selected from grades three, four and five respectively for a total sample of 24 .

\section{Students}

Four teams interviewed the boys. The interviews followed a structured questionnaire and care was taken to ensure accuracy and consistency. The interview questions were designed by the Kent State team to gather information regarding demographics, the students' level of: interest in school, extracurricular activities, perceived rewards for school success, the availability and use of computers and other technology.

\section{Teachers}

Teachers responded to a specifically developed questionnaire that collected information regarding their qualifications, their perceptions of male student needs and abilities as well as their personal proficiency with computers and other technology.

\section{䙫esules}

\section{Strudents}

Data were obtained from a sample of 93 boys randomly selected from public schools in New Providence. The boys were in third, fourth and fifth grade and approximately equally distributed among the three grades. The subjects ranged in age from 7 to 15.

Forty-nine percent of the sample indicated that they lived with a caregiver who was female and the majority (74\%) of them reported that they were likely to discuss school issues with a female, usually their mother or other female family member (see Figure 1). When the boys received help with homework, $80 \%$ of the time it was help from a mother. On average, mothers were more likely to attend Parent Teacher Association (PTA) meetings, collect report cards and talk to teachers about progress in school (35\%), followed by sister and aunt respectively.

When not in school, $41 \%$ of students reported that in addition to typical activities such as sports, cycling or skateboarding, they read or did school 


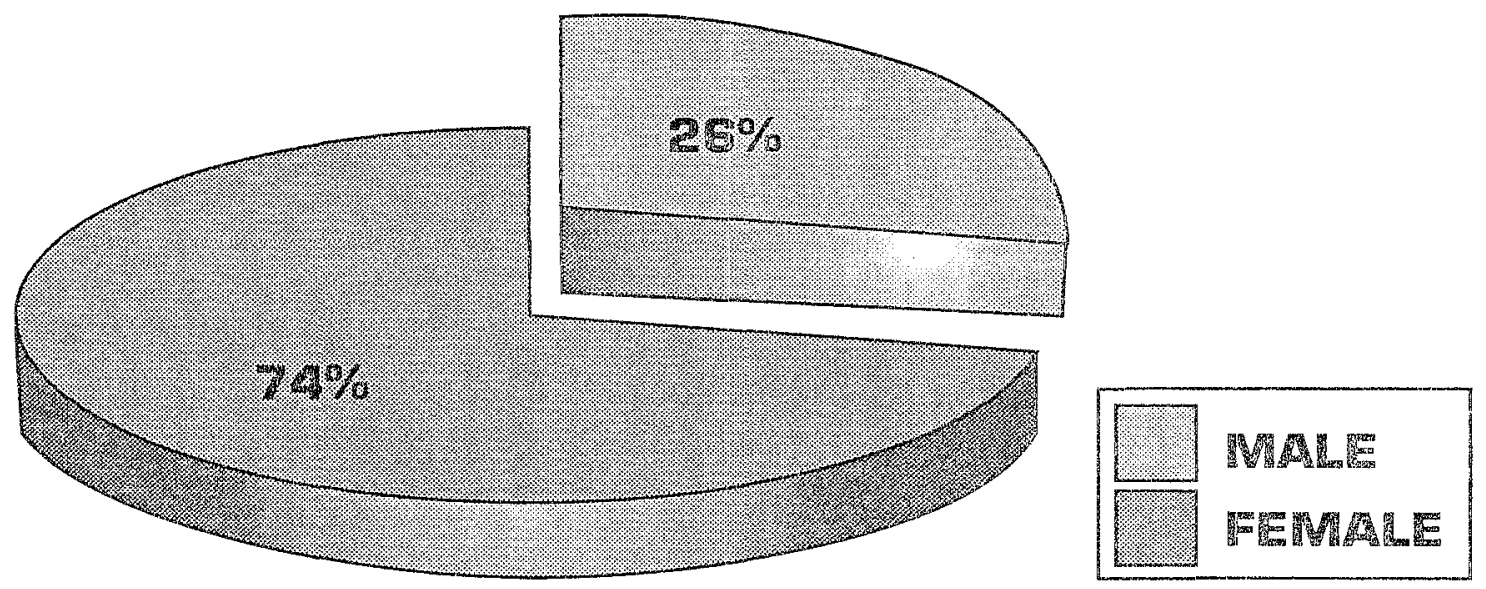

Figure 1 Proportion of students who discuss school issues with a male or a female $N=94$

work. Only $16 \%$ chose to indicate that they watched television, however, later in the interview when queried, $67 \%$ of the students reported that they did watch television everyday and $63 \%$ of these indicated that they could watch television whenever they wanted. When asked the last time that they had read a book at home, $85 \%$ said they had read a book within the last week, $43 \%$ said that they had read a book yesterday and $2 \%$ indicated that they did not read.

The majority of students endorsed mathematics both as the subject they liked best and the subject at which they performed best.

Ninety-eight percent reported that their family viewed school as important and $69 \%$ said that they had been encouraged in one way or another.

$+\infty$

Thirty percent indicated that they knew a male who attended The College of The Bahamas, and 8-9\% knew a male who attended Bahamas Technical and Vocational Institute or the Bahamas Baptist Community College.

Students reported that the person that they admired the most was their mother (31\%) followed by their father (18\%) and the prime minister (13\%). Of the remaining persons, males were named three times more often than females. The reason the person was named as most admired was most often ( $22 \%$ of responses) because "they are a nice loving person".

Generally, in terms of technological exposure, students were familiar with common applications of tools such as a calculator, audio and video recorder/player, and a still camera. Sixty-five percent have been shown how to use a computer. Students more frequently have access to technological tools in the home. The most common tool used for school applications is the calculator; some students have used an audio or video recorder/player, and a still camera for school applications. Fifty-four percent have used a computer for schoolwork purposes. Students most often reported that the computer is their favourite technological tool.

\section{Teachers}

All of the teachers surveyed were female, the majority being between 40 to 49 years old, with a mean of 21 years experience, and $75 \%$ held a Bachelor- 
level degree. Initial analysis of the qualitative data revealed that teachers had a recurring concern about absentee fathers and the male students' need for paternal love and support. Academically, the teachers were concerned with students' reading skills, motivation and attitude toward learning.

Few teachers reported the use of technological equipment in the classroom. Ninety percent indicated that computer equipment was not available in their schools. Fifty-five percent reported allowing access to technologies (e.g. computer or video) as a reward for work done in the classroom. Teachers generally reported low personal proficiency with computers; only $13 \%$ indicated advanced competency. They estimated that, on average, 28\% of their students have access to a computer at home.

Teachers indicated that parents were more likely to attend on report card days as opposed to PTA meetings. Parents were described, on average, as more supportive of discipline and extracurricular activities than homework. Teachers frequently verbalized a belief in the lack of parental involvement and lack of disciplinary action as contributing to male underachievement.

\section{Meussion}

Salient in the findings are indications that for the most part, boys tended to perceive education as important and certainly they reported being encouraged to attend and achieve at school. They tended to verbalize the importance and their appreciation of a good education. This attitude appeared to reflect a strong influence of family on their desire to do well in school. They often reported parents encouraging them to attend and do well. Teachers, who were predominantly female, failed to recognize this influence and were more likely to identify a lack of parental involvement coupled with a lack of discipline as a cause of male underachievement. It remains to be seen whether it is this discrepancy that is a precipitating factor of purported academic alienation of young Bahamian males.

Students reported that they were partial to math and that it was their strongest subject. This suggests that these boys perceived their effort and achievement in a positive light. They have had some exposure to technological tools and were generally enthusiastic about computer use. The enthusiasm for technology apparent at this level, despite the lack of resources in the schools, was likely supported in part from home.

Emerging from the data was a strong female influence in the lives of the boys in this study. Boys report that they most often talked to their mother about educational issues; that she helped with schoolwork and was likely to be the one who attended school on their behalf. In fact many did say that the person they admired the most was their mother; this was likely due to the fact that females were more likely to be the head of single households. Female influence at the family level is one factor that has been found to influence male underachievement in other countries. However, with respect to this study, there was no apparent pattern that indicated that boys are not invested in school at this point. Certainly if indicators are expected to emerge that boys are starting to become disenfranchised, it was not evident in this study.

This pllot study has served to provide a starting point for research into educational achievement in The Bahamas. In the future, information regarding 
discrepancies between potential and achievement needs to be explored. A more comprehensive study exploring factors that influence male achievement is planned.

\section{Pereremes}

Allen, R., \& Kickbusch, K. (1998). Variables affecting student achievement. In Teaching \& learning: primer: education issues. Retrieved from the Wisconsin Education Association Council Web site: http://www.weac.org/Resource/ Primer98/variable.htm.

Bridges, R.E. (1999). Improving academic achievement for the black male child: An outline of key points to be considered: Retrieved from the North Carolina Department of Public Instruction Web site: http://www.ncpublicschools.org/closingthegap/1999/bridges.html.

Ford, D.Y., \& Thomas, A. (1997). Underachievement among gifted minority students: Problems and promises. Eric Digest E544. Retrieved from http://www.ed.gov/databases/ERIC_Digests/ed409660.html

Francis, B. (1999). Lads, lassies and (new) Labour: 14-16 year-old students' responses to the "laddish behaviour and boys' underachievement" debate. [Electronic version]. British Journal of Sociology of Education, 20, 355-371.

Lee, C.C. (1991). Empowering young black males. ERIC Digest. Retrieved from http://www.ed.gov/databases/ERIC_Digests/ed341887.html.

Lee, C.C. (2001). The black male in contemporary society: Societal and educational challenges. Retrieved February 25, 2001 from the ERIC/CASS Virtual Library Web site: http://ericcass.uncg.edu/virtuallib/achievement/8003.html.

Ministry of Economic Development. (1997). Report of the 1990 census of population and housing. Nassau: Author.

-Noguera, P. (1996). Black male crisis. [Electronic version]. The Journal of Negro Education 65(2), 1-29.

Rolle, D. (2000, March 8). Colleagues seek ways to lure more men into the classroom. The Tribune. p. 5.

Stubbs, E. (1999-2000). Students competence: A statistical analysis of student placement, relative to grade and age in the public school system: Vol. 4 - New Providence. Nassau: Ministry of Education, Planning Unit.

UNESCO (2000). EFA in the Caribbean: Assessment 2000 Bahamas Country Report. Retrieved from http://www2.unesco.org/wef/countryreports/ bahamas/contents.html.

JESSICA MINNIS is a Senior Lecturer in the Department of Sociology in the School of Social Sciences. She is currently Chairperson of the School of Social Sciences, The College of The Bahamas.

SUSAN PLUMRIDGE is a Lecturer in the Department of Psychology in the School of Social Sciences, The College of The Bahamas.

CEPHAS WARD is a Lecturer in the Department of Mathematics in the School of Natural Sciences and Environmental Studies, The College of The Bahamas. 